\begin{tabular}{|c|c|}
\hline Citation & $\begin{array}{l}\text { Sarafianos, Athanasios; Pichler, Joachim; Sandner, Christoph; Steyaert, } \\
\text { Michiel, (2015), } \\
\text { "A folding dickson-based fully integrated wide input range capacitive } \\
\text { DC-DC converter achieving Vout/2-resolution and } 71 \% \text { average } \\
\text { efficiency, } \\
\text { in Solid-State Circuits Conference (A-SSCC), } 2015 \text { IEEE Asian, vol., no., } \\
\text { pp.1-4, 9-11 Nov. } 2015\end{array}$ \\
\hline Archived version & $\begin{array}{l}\text { Author manuscript: the content is identical to the content of the published } \\
\text { paper, but without the final typesetting by the publisher }\end{array}$ \\
\hline Published version & http://dx.doi.org/10.1109/ASSCC.2015.7387488 \\
\hline Journal homepage & http://www.a-sscc2015.org/ \\
\hline Author contact & $\begin{array}{l}\text { your email aki.sarafianos@esat.kuleuven.be } \\
+32(0) 16321086\end{array}$ \\
\hline
\end{tabular}

(article begins on next page) 


\title{
A Folding Dickson-based Fully Integrated Wide Input Range Capacitive DC-DC Converter achieving Vout/2-Resolution and 71\% Average Efficiency
}

\author{
Athanasios Sarafianos ${ }^{1}$, Joachim Pichler ${ }^{2}$, Christoph Sandner ${ }^{2}$ and Michiel Steyaert ${ }^{1}$ \\ 'ESAT-MICAS, K.U. Leuven Kasteelpark Arenberg 10, B-3001 Leuven, Belgium \\ ${ }^{2}$ Infineon Technologies Austria AG, Villach 9500, Austria \\ Email: \{asarafia,steyaert\}@esat.kuleuven.be, \{Joachim.Pichler,Christoph.Sandner\}@infineon.com
}

\begin{abstract}
This paper presents a fully integrated capacitive DC-DC converter with a wide input voltage range. The folding Dickson converter is used to implement four discrete voltage conversion ratios, capable of operating over a wide input voltage range. A subconverter is added, enabling four additional voltage conversion ratios, improving the input voltage resolution from $V_{\text {out }}$ to $\frac{1}{2} V_{\text {out }}$. This way, the extra conversion ratios increase the overall efficiency, and at the same time reduce output ripple specifications. Implementing this additional converter at the end of the Dickson cascade reduces the complexity of driving the extra power train switches. This improved folding Dickson converter achieves an average efficiency above $70 \%$ at maximum output power, and operates over an input voltage range of $2.5-8 \mathrm{~V}$ for an output voltage of $1.2 \mathrm{~V}$. The converter has been implemented and validated in a standard $90 \mathrm{~nm}$ technology.
\end{abstract}

(Keywords: Monolithic, Wide Input Range, Switched Capacitor and DC-DC Converter)

\section{INTRODUCTION}

High power density [1], [2], ultra-low ripple [3] and very fast transient response [4] designs have appeared in state-ofthe-art fully integrated switched capacitor DC-DC converters and are bringing the topic to a state of maturity. However, few designs employ gearboxing to a large extent, usually limited to 2-3 topologies [3]-[6], and those that do never stray far from the $V_{\mathrm{dd}}$ of the used technology. In [7], DAC-like techniques give rise to a great number of voltage conversion ratios (VCRs), allthough at reduced output powers.

This paper introduces an improvement on the folding Dickson converter as presented in [8], which has an input voltage range of $>4 V_{d d}$, but suffers from reduced efficiency at higher conversion ratios, and requires high levels of fragmentations to keep the output ripple in check. Several insights and the addition of an extra subconverter, which is used to implement four extra topologies, allow us to maintain a high efficiency over a wide input voltage range.

This paper is organised as follows. In Section II, the design and operation of the converter is discussed, along with certain key insights. Section III presents the measurement results and compares the adapted folding Dickson converter with other fully integrated gearbox designs, before finally drawing conclusions in Section IV.



Fig. 1. System overview of the folding Dickson-based converter.

\section{SyStem OVERVIEW AND OPERATION}

\section{A. The Folding Dickson Converter}

Fig. 1 shows the schematic of the fragments, which are controlled by an on-chip hysteretic control loop. The converter builds further upon the folding Dickson converter, as seen in [8], which implements $\mathrm{N}$ voltage conversion ratios for an $\mathrm{N}$-stage Dickson converter. Folding is realised by virtually merging the top and bottom plates of two or more flying capacitors, creating an equivalent lumped flying capacitor (Fig. 5). Merging is realised by changing the clock of the power train switches. Dedicated converters [8] generate the voltage supply required to drive flying switches $M_{1-4}$, whose operating conditions depend on input voltage and VCR. For a four stage Dickson converter, four topologies $\left(\frac{1}{2}, \frac{1}{3}, \frac{1}{4}, \frac{1}{5}\right)$ are realised.

\section{B. Improved Folding Dickson Converter}

With the addition of the subconverter (see Fig. 3), four additional topologies $\left(\frac{2}{3}, \frac{2}{5}, \frac{2}{7}, \frac{2}{9}\right)$ are possible, while leaving the operation of the folding Dickson converter unhampered. These extra topologies increase the overall efficiency over the input voltage range, and relax the ripple requirements, since each topology needs to cover a shorter range of $V_{i n}$ (leading to an increased input voltage resolution), and both are related to 


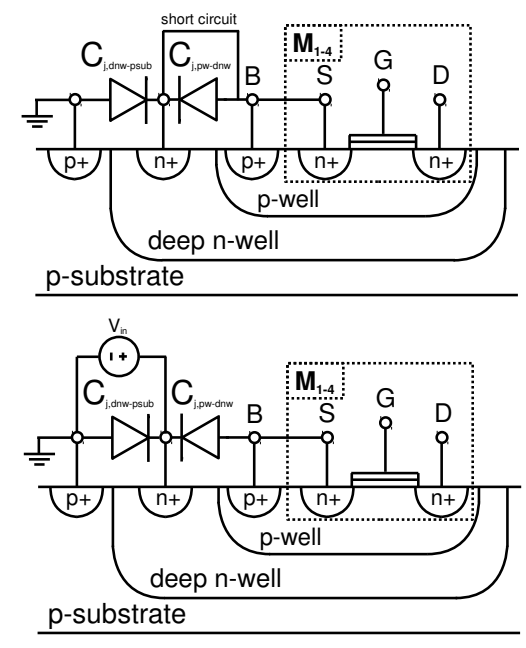

Fig. 2. Two well biasing strategies for power train switches $M_{1-4}$. In this implementation, the second option is chosen.

$\gamma=\frac{V_{o}}{V_{i n} V C R}$ in the SSL-region [9].

Two additional design strategies allow us to maintain a good efficiency even for the higher conversion ratios:

1) Sizing of the switches by using a parasitic capacitancebased optimisation per topology, followed by a weighted average distribution. Instead of using a $G \cdot V^{2}$-metric for the switches, the following is used (as seen in [9]):

$$
M_{s w, i}=\frac{G_{i}\left(v_{\text {rated }, i}\right)^{2}}{C_{G} v_{G}^{2}, i+C_{D} v_{\text {rated }, i}^{2}+C_{B} v_{B, i}^{2}}
$$

with $C_{G}, C_{D}$ and $C_{B}$ the parasitic gate, drain-source and bulk capacitance, $G$ the conductance per area, $v_{\text {rated }}$ the maximum drain-source voltage, and $v_{G}$ and $v_{B}$ the voltage swing seen at the gate and bulk. Using this switch metric along with an energy loss cost constraint, switch sizing can be optimised for a given $R_{F S L}$ and lowest parasitic losses [9].

2) Two approaches exist to bias the triple well structure of switches $M_{1-4}$. One is to short bulk, source and deep n-well together, preventing this first junction from conducting, as well as keeping the psub/deep n-well junction reversely biased. However, this means that the large junction capacitance $C_{j, d n w-p s u b}$ is subject to the voltage swing, causing increased parasitic losses. The other approach is to bias the $\mathrm{N}$-well of isolated switches $\mathrm{M}_{1-4}$ with $\mathrm{V}_{\text {in }}$. $\mathrm{V}_{\text {in }}$ is additionally decoupled, and the voltage swing is seen over the smaller junction capacitance $C_{j, p w-d n w}$, while keeping all junctions reversely biased (see fig. 2). In this implementation, the latter option is chosen.

\section{Subconverter Operation}

A detailed schematic of the subconverter is shown in Fig. 3 , while the detailed gate drive signals and capacitor terminal voltages are shown in Fig. 4. In the $\frac{1}{x}$-mode, $\mathrm{M}_{5}$ is turned off in phase phi ${ }_{1}$, while it is conducting in phi $_{2}$, and capacitor $\mathrm{C}_{5}$ is in parallel with $\mathrm{C}_{4}$ in both phases (Fig. 5), which leads to the default folding Dickson converters, and allows operation in the $\frac{1}{2}-, \frac{1}{3}-, \frac{1}{4}$ - and $\frac{1}{5}$-modes.

In the $\frac{2}{x}$-mode however, $\mathrm{C}_{4}$ and $\mathrm{C}_{5}$ are connected in parallel in $\mathrm{phi}_{1}$, and connected in series in $\mathrm{phi}_{2}$. To implement this converter, 5 additional switches $\left(\mathrm{M}_{14-18}\right)$ are required, as well as dynamic bulk biasing for $\mathrm{M}_{5}$.

In the $\frac{2}{x}$-mode, the drain of $\mathrm{M}_{5 \mathrm{c}}$ drops below $\mathrm{V}_{\text {out }}$, which would cause $\mathrm{M}_{5}$ to turn on, and cause its body diode to start

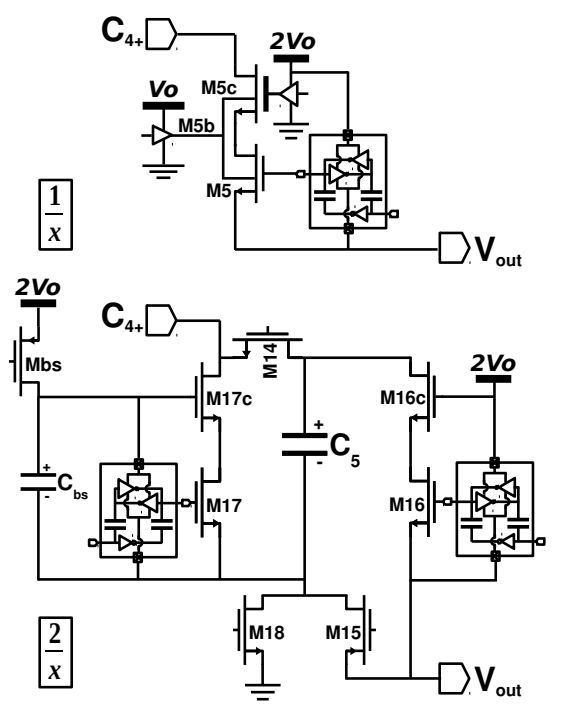

Fig. 3. Subconverter used to implement $\frac{1}{x}$ and $\frac{2}{x}$ conversion ratios.

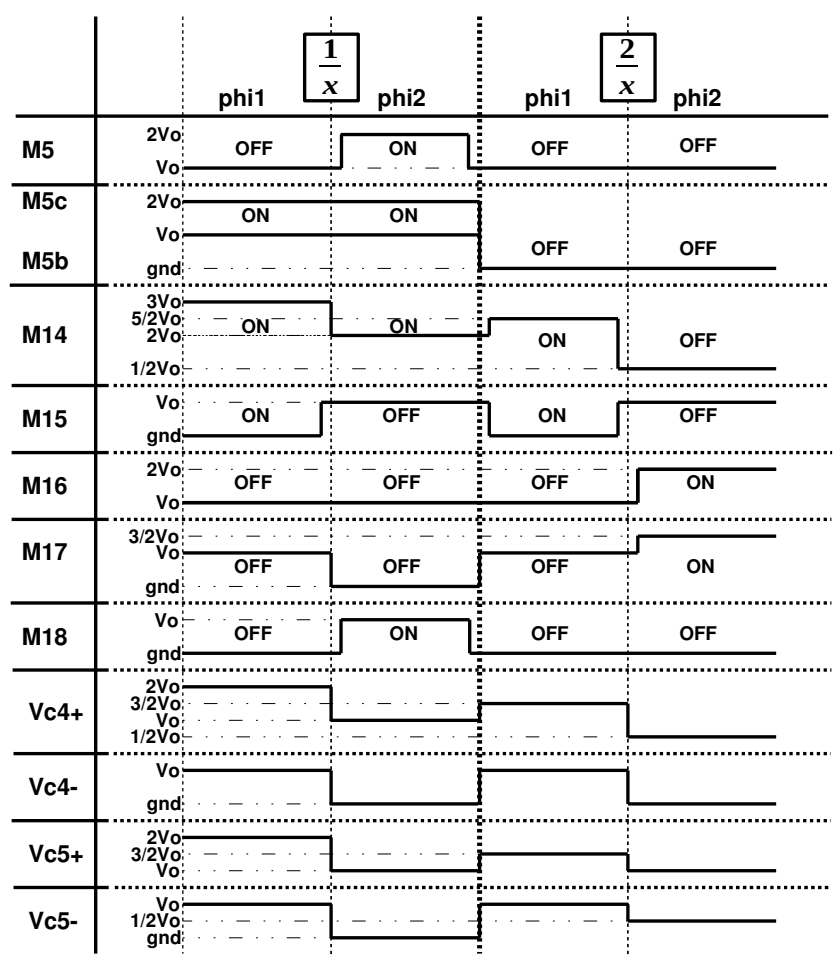

Fig. 4. Switching signals and voltages of the subconverter. 


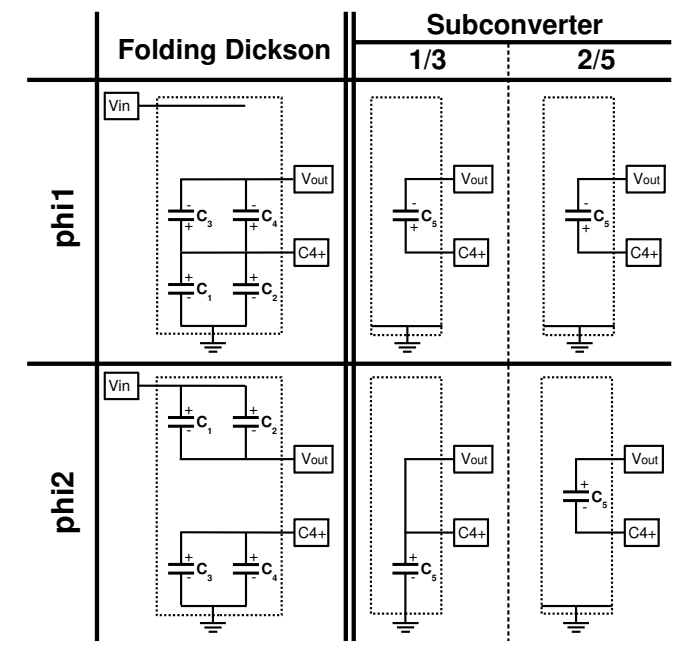

Fig. 5. Example converter operation in the $\frac{1}{3}$ - and $\frac{2}{5}$-mode.

conducting. To prevent this, the bulk is connected to ground, as well as the gate of $\mathrm{M}_{5 \mathrm{c}}$. In the $\frac{1}{x}$-mode, the gate of $\mathrm{M}_{5 \mathrm{c}}$ is connected to $2 \mathrm{~V}_{\text {out }}$, generated by an on-chip voltage doubler (see Fig. 1), and the bulk is connected to $\mathrm{V}_{\text {out }}$.

$\mathrm{M}_{15}$ and $\mathrm{M}_{18}$ reside between $\mathrm{V}_{\text {out }}$ and ground, which requires no special gate drive. $\mathrm{M}_{16}$ is driven from the on chip $2 \mathrm{~V}_{\text {out }}$ supply, since it's source is connected to $\mathrm{V}_{\text {out }}$. To drive $\mathrm{M}_{17}$, an additional bootstrapping circuit is introduced. When $\mathrm{C}_{5}^{-}$is connected to $\mathrm{V}_{\text {out }}$, which occurs in both modi, $\mathrm{M}_{\mathrm{bs}}$ turns on, and $\mathrm{C}_{\mathrm{bs}}$ is charged from the $2 \mathrm{~V}_{\text {out }}$-supply to $\mathrm{V}_{\text {out }}$. In the other phase, $\mathrm{C}_{\mathrm{bs}}$ can be used to turn on $\mathrm{M}_{17}$, if required. The voltage over $C_{b s}$ is also used to bias cascode $M_{17 c}$. $M_{b s}$ and $\mathrm{C}_{\mathrm{bs}}$ are sized to achieve a time constant of $\tau_{\mathrm{bs}}=\frac{\mathrm{T}_{\mathrm{sw} \text { min }}}{5}$, and to allow a discharge of $10 \%$ when turning on $\mathrm{M}_{17}$.

Since the source of $\mathrm{M}_{14}$ is connected to $\mathrm{C}_{4+}$, the floating rail generated by the fourth Bootstrapped Gate Boost Converter (BGBC4) can be used to turn on this switch. These BGBC's use bootstrapping to copy the flying capacitor's top plate voltage, and charge a floating capacitor to $\mathrm{V}_{\text {out }}$, which is then used to turn on switches $\mathrm{M}_{1-4,14}$ and to bias their cascodes. The full operation and detail of the BGBC circuits can be found in [8]. As an example, Fig. 5 shows how the two modi are translated to the flying capacitor arrangement in the $\frac{1}{3}$ - and the $\frac{2}{5}$-mode.

Flying capacitors are implemented using stacked MOM and MIM capacitors to increase density, for a total of $1.64 \mathrm{nF}$. Output decoupling is done with $4 \mathrm{nF}$ MOSCAPs, while the input is decoupled with $400 \mathrm{pF}$ MOMCAP, capable of dealing with higher voltages.

\section{Measurements}

The efficiency has been measured over one decade of output power $(2 \mathrm{~mW}-20 \mathrm{~mW})$, while the output voltage is regulated to $1.2 \mathrm{~V}$. For $\mathrm{P}_{\text {out }}=20 \mathrm{~mW}$, the efficiency and input current are shown in Fig. 6. Besides the efficiency, Fig. 6 also shows the measured input current of the converter, and the ideal input current of a generic DC-DC converter with a fixed output

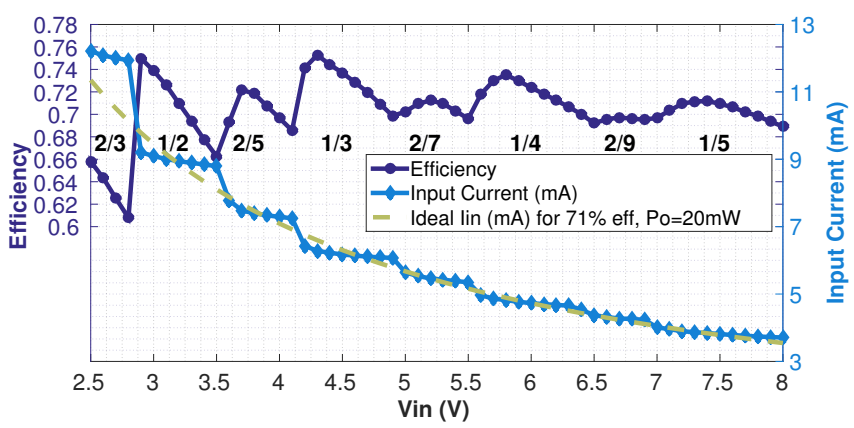

Fig. 6. Measured efficiency and input current (and ideal input current) for $\mathrm{P}_{\text {out }}=20 \mathrm{~mW}$, over $\mathrm{V}_{\text {in }}$.

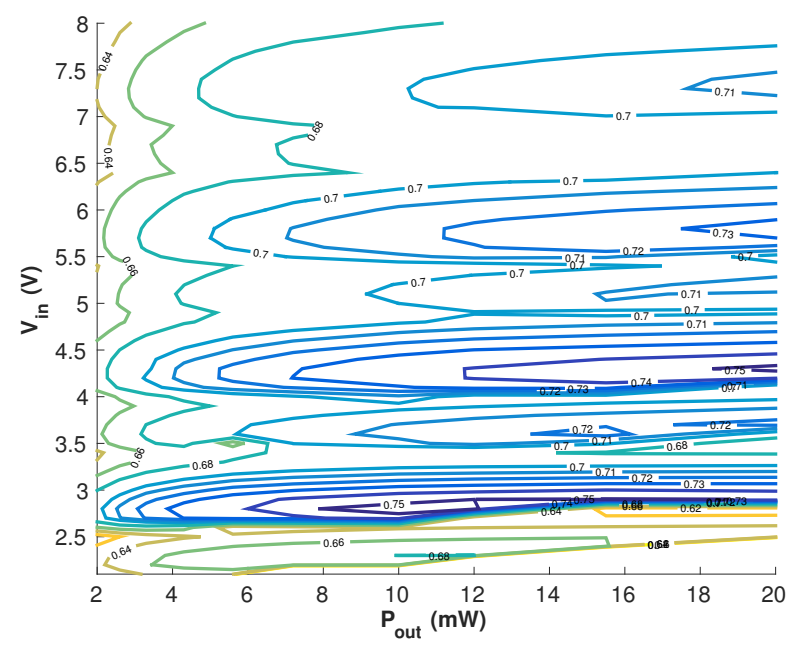

Fig. 7. Measured efficiencies for $P_{\text {out }}=2-20 \mathrm{~mW}$ and $V_{\text {in }}=2 \cdot 1-8 \mathrm{~V}$.

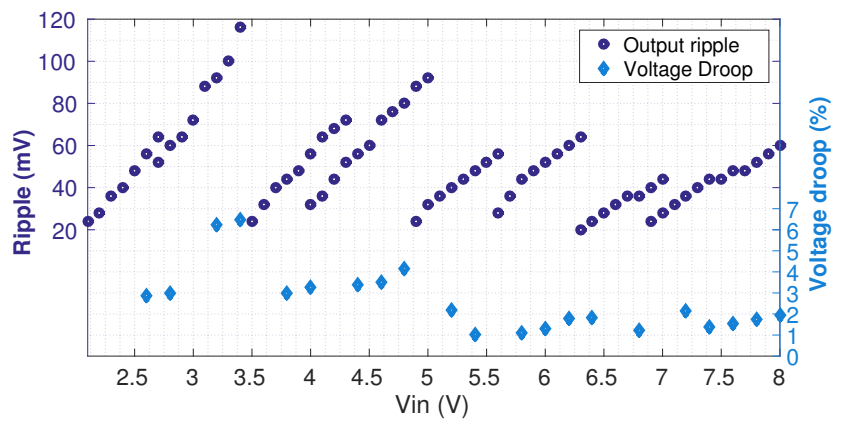

Fig. 8. Measured maximum output ripple, and load transient $\left(\mathrm{I}_{\text {out }}=1.67 \mathrm{~mA} \rightarrow 11.67 \mathrm{~mA}\right)$ as a function of input voltage.

power and an efficiency of $71 \%$. Interestingly, it is seen that both input currents match closely, allowing the converter to keep its efficiency fairly constant. Increasing the resolution of the converter would allow to match this generic converter even more closely.

At maximum output power, efficiencies up to $75 \%$ are recorded in the $\frac{1}{2}$ - and $\frac{1}{3}$-topologies, while most other topologies achieve peak efficiencies above $70 \%$. Conversion ratio $\frac{2}{9}$ achieves the lowest peak efficiency, since its switching frequency is highest of all conversion ratios for a given $R_{S S L}$ 


\begin{tabular}{|c|c|c|c|c|c|c|c|}
\hline Work & [2] & [3] & [4] & [5] & [7] & [8] & This work \\
\hline technology & $32 \mathrm{~nm}$ SOI & 90nm CMOS & 65nm LP CMOS & 28nm FD-SOI & $0.25 \mu \mathrm{m}$ CMOS & 90nm CMOS & 90nm CMOS \\
\hline$V C R s$ & $\frac{2}{3}, \frac{1}{2}, \frac{1}{3}$ & $\frac{2}{3}, \frac{1}{2}$ & $\frac{2}{5}, \frac{1}{3}$ & $\frac{5}{2}, \frac{2}{1}, \frac{3}{2}$ & 4-bit recursive & $\left(\frac{1}{2}, \frac{1}{3}, \frac{1}{4}, \frac{1}{5}\right)$ & $\frac{2}{3}, \frac{1}{2}, \frac{2}{5}, \frac{1}{3}, \frac{2}{7}, \frac{1}{4}, \frac{2}{9}, \frac{1}{5}$ \\
\hline$C_{f l y}$ & моs & $1.15 \mathrm{nF}$ мо(м/s) & $3.88 \mathrm{nF}$ мов & $\mathrm{MO}(\mathrm{M} / \mathrm{s})$ & $3 \mathrm{nF}$ мім & $2 \mathrm{nF}$ мім & $1.64 \mathrm{nF}_{\text {м(I/) }}$ \\
\hline$\rho_{\text {(mW/mm2) }}$ & 550 & 38.6 & 190 & 4.9 & 0.94 & 16.3 & 13.3 \\
\hline$\eta_{\text {avg }}$ & $66.5 \%$ & $81 \%$ & $74.3 \%$ & $88 \%$ & $69.2 \%$ & $67 \%$ & $71 \%$ \\
\hline$V_{\text {out }}$ & $0.55-1.1 \mathrm{~V}$ & $0.7 \mathrm{~V}$ & $1 \mathrm{~V}$ & $1.2-2.4 \mathrm{~V}$ & $0.1-2.18 \mathrm{~V}$ & $1.2 \mathrm{~V}$ & $1.2 \mathrm{~V}$ \\
\hline$V_{\text {in }}$ & $2 \mathrm{~V}$ & $1.2-2 \mathrm{~V}$ & $3-4 \mathrm{~V}$ & $1 \mathrm{~V}$ & $2.5 \mathrm{~V}$ & $2.8-8 \mathrm{~V}$ & $2.5-8 \mathrm{~V}$ \\
\hline
\end{tabular}

TABLE I: Comparison with other fully integrated gearbox DC-DC converters.

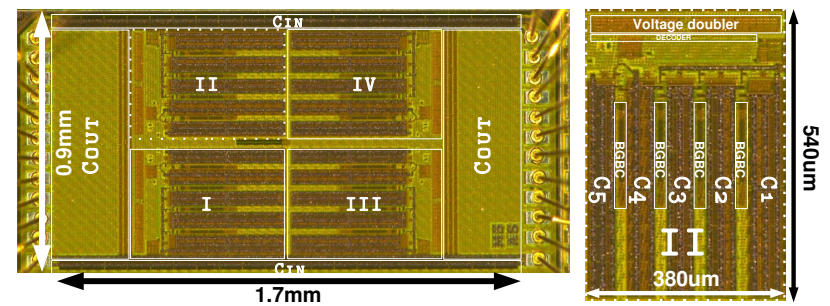

Fig. 9. Chip micrograph of the folding Dickson-based converter, and detail of one fragment.

[9]. However, it still achieves a peak efficiency of $69.7 \%$.

The contour plot of the efficiency over $\mathrm{V}_{\text {in }}$ and $\mathrm{P}_{\text {out }}$ can be seen in Fig. $7 . \mathrm{V}_{\text {in }}$ ranges from $2.5 \mathrm{~V}$ to $8 \mathrm{~V}$, allthough at power backoff the converter is able to work down to $2.1 \mathrm{~V}$. Efficiencies above $65 \%$ are seen over almost the entire range, and the average efficiency remains between $66 \%$ and $71 \%$ for the measured output power range.

Fig. 8 shows the maximum observed ripple during measurements. Step down ratio $\frac{1}{2}$ suffers most from increased output ripple due to its fast switching frequency backoff, but remains nonetheless below $10 \%$ of the output voltage. Also shown is the load transient response for an increase of $10 \mathrm{~mA} / 8 \mathrm{~ns}$ in output current. Slew rate was limited by the off-chip load.

The chip micrograph can be seen in Fig. 9, along with a detailed figure of one fragment. The fragment shows the position of the decoding logic, on-chip voltage doubler, flying capacitors and helper converters (BGBCs).

A comparison with other gearbox designs is made in Fig. 10 and table I. While the power density of this design is neither high nor low compared to other designs, this DCDC converter stands out at the achieved input voltage range, which is over 4.5 times the $V_{d d}$ of this technology. Other designs achieve better average efficiencies, allthough over a much smaller input/output voltage range.

\section{CONCLUSION}

The design, operation and measurement results of an improved folding Dickson converter have been discussed in this paper. By implementing an additional subconverter with 5 switches and 1 flying capacitor, four extra topologies are implemented, improving the input voltage resolution, having each topology operate over $0.6 \mathrm{~V} \mathrm{~V} \mathrm{~V}_{\text {in }}$-range $\left(\frac{1}{2} \mathrm{~V}_{\text {out }}\right)$ instead
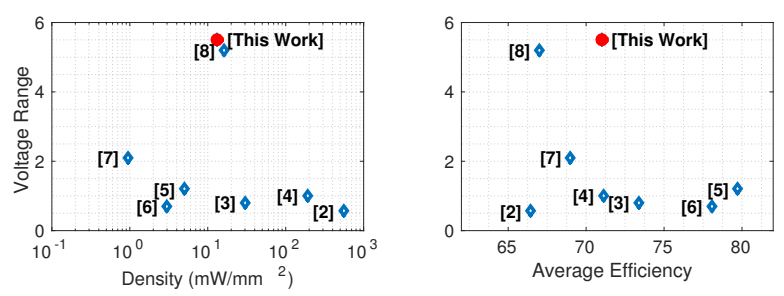

Fig. 10. Comparison of voltage range, power density and average efficiency of several monolithic gearbox converters.

of $1.2 \mathrm{~V}\left(\mathrm{~V}_{\text {out }}\right)$. This allows the converter to maintain high overall efficiencies, while mitigating demands on the output ripple. Peak efficiencies are measured up to $75 \%$, with an average efficiency of $71 \%$ over the input range of $2.5-8 \mathrm{~V}$. This subconverter does not interfere with the folding Dickson's operation, which can be extended to any number of stages.

\section{REFERENCES}

[1] H. Meyvaert, T. Van Breussegem, and M. Steyaert, "A 1.65w fully integrated $90 \mathrm{~nm}$ bulk cmos intrinsic charge recycling capacitive dc-dc converter: Design techniques for high power density," in IEEE Energy Conversion Congress and Exposition, Sept 2011, pp. 3234-3241.

[2] H.-P. Le, S. Sanders, and E. Alon, "Design techniques for fully integrated switched-capacitor dc-dc converters," IEEE J. Solid-State Circuits, vol. 46, no. 9, pp. 2120-2131, Sept 2011.

[3] G. Pique, "A 41-phase switched-capacitor power converter with $3.8 \mathrm{mv}$ output ripple and $81 \%$ efficiency in baseline 90nm cmos," in Proc. IEEE Int. Solid-State Circuits Conf. Dig. Tech. Papers (ISSCC), Feb 2012, pp. 98-100.

[4] H.-P. Le, J. Crossley, S. Sanders, and E. Alon, "A sub-ns response fully integrated battery-connected switched-capacitor voltage regulator delivering $0.19 \mathrm{w} / \mathrm{mm} 2$ at $73 \%$ efficiency," in Proc. IEEE Int. Solid-State Circuits Conf. Dig. Tech. Papers (ISSCC), Feb 2013, pp. 372-373.

[5] A. Biswas, Y. Sinangil, and A. Chandrakasan, "A 28nm fdsoi integrated reconfigurable switched-capacitor based step-up dc-dc converter with 88\% peak efficiency," in Proc. ESSCIRC, Sept 2014, pp. 271-274.

[6] D. El-Damak, S. Bandyopadhyay, and A. Chandrakasan, "A $93 \%$ efficiency reconfigurable switched-capacitor dc-dc converter using on-chip ferroelectric capacitors," in Proc. IEEE Int. Solid-State Circuits Conf. Dig. Tech. Papers (ISSCC), Feb 2013, pp. 374-375.

[7] L. Salem and P. Mercier, " 4.6 an $85 \%$-efficiency fully integrated 15ratio recursive switched-capacitor dc-dc converter with 0.1-to-2.2v output voltage range," in Proc. IEEE Int. Solid-State Circuits Conf. Dig. Tech. Papers (ISSCC), Feb 2014, pp. 88-89.

[8] A. Sarafianos and M. Steyaert, "Fully integrated wide input voltage range capacitive dc-dc converters: The folding dickson converter," Solid-State Circuits, IEEE Journal of, no. 99, pp. 1-11, July 2015.

[9] M. Seeman, A Design Methodology for Switched-Capacitor DC-DC Converters. University of California at Berkeley, 2009. 